\title{
Hydrogen-Bonded Copper Coordination Architectures: A CSD Study Based Magneto-Structural Analysis
}

\author{
Archana Yadav, Kafeel Ahmad Siddiqui* \\ Department of Chemistry, National Institute of Technology Raipur \\ G. E. Road Raipur-492010, Chhattisgarh, India
}

\begin{abstract}
The metal-organic supramolecular synthons like $\left.\{\cdots \mathrm{O}-\mathrm{Cu}-\mathrm{O}-\mathrm{H}\}_{2}, \quad[\cdots \mathrm{O}-\mathrm{C}-\mathrm{O}-\mathrm{Cu}-\mathrm{O}-\mathrm{H}\}_{2}, \quad{ }^{\prime} \mathrm{O}-\mathrm{C}-\mathrm{O}-\mathrm{Cu}-\mathrm{N}-\mathrm{N}-\mathrm{H}\right\}_{2}$, etc., were pointed out by using Cambridge Structural Data Base (CSD) Mining. The present work describes the relationship between magnetic properties and 'd' in metal-organic synthons of discussed coordination complexes. The analysis reveals that most of the complexes show ' $J$ ' value if ' $d$ ' and $C u^{\prime \cdots} C \mathrm{Cu}$ distances are in the range of 2.5 to $2.9 \dot{A}$ and 6.5 to $7.9 \dot{A}$ respectively.
\end{abstract}

Keywords: Copper complexes, Hydrogen bond, Magnetic interactions, Supramolecular synthon.

\section{INTRODUCTION}

In crystal engineering, supramolecular synthons have contemporary research attentiveness towards the design and synthesis of new families of metal-organic complexes using multidentate ligands involving non-covalent interactions from crystal structures with specific functions or properties. The most imperative factor of this supramolecular interaction involving hydrogen bond has consequently potential applications in magnetic properties. In this context, an assessment of the crystal and their desired structureproperty relationship govern by magnetic exchange pathways mediated by complementary hydrogen bonding interactions has been discussed.

Magneto-structural analysis with non-covalent $\mathrm{Cu}^{\cdots}{ }^{\cdots} \mathrm{Cu}$ interaction $(>4.0 \AA \hat{)})$ is of a particular interaction. Copper chemistry is widely described experimentally ${ }^{1-6}$ and addressed theoretically ${ }^{7,8}$ in magneto-structural point of view, especially concerning hydrogen-bonded binuclear systems. These $\mathrm{Cu}$ (II) complexes show ferromagnetic/antiferromagnetic coupling depending on their geometry. In the addition, these are of theoretical interest as they provide examples of magnetic interactions with an unpaired electron.

The article focuses on how the presence of hydrogen bonds regulates the magneto-structural diversity in H-bonded metal-organic coordination complexes. The analysis was done by using the data retrieved by the CSD search. The search was carried out as organometallic, single-crystal structures, with 3D coordinates present, being non-polymeric, error free, and with no disorder. The distance, d, between acceptor and $\mathrm{H}$ was constrained to lie between 1.8 and $3.8 \AA$. with the upper limit determined by the sum of the respective van der Waals radii plus about $10 \%$ to capture all possible interactions.

\section{MATERIALS AND METHODS}

CONQUEST $^{9}$ - The Cambridge Crystallographic Data Centre was used to search and retrieve the information metallosupramolecular networks from the Cambridge Structural Database ${ }^{10}$ (version 5.40 CSD update 2 - 2019). The obtained geometrical data was further analyzed for reliable conclusions about the nature of intermolecular hydrogen bonding in the supramolecular network. The analysis and demonstration of the structures were performed using PLATON ${ }^{11}$, MERCURY ${ }^{12}$, and DIAMOND $^{13}$.

\section{MAGNETO-STRUCTURAL ANALYSIS}

The representative structures among $\mathrm{Cu}$-coordination complexes retrieved from CSD search are discussed one by one. One of the hydrogen bonding parameters ' $\mathrm{d}$ ', $\mathrm{Cu} \cdots \mathrm{Cu}$ distances, and isotropic interaction parameter $\mathrm{J}, \Theta$ of listed copper complexes are tabulated in Table 1. 
International Journal of Advances in Scientific Research and Engineering (ijasre), Vol 7 (3), March -2021

Table 1. Hydrogen bonding parameter ' $d$ ', $\mathrm{Cu}$ “. $\mathrm{Cu}$ distances, and isotropic interaction parameter $\mathrm{J}$

\begin{tabular}{|c|c|c|c|c|c|c|c|}
\hline \multirow{2}{*}{$\begin{array}{l}\text { S. } \\
\text { No. }\end{array}$} & \multirow{2}{*}{ Code } & \multirow{2}{*}{ Dimer } & \multirow{2}{*}{\multicolumn{2}{|c|}{$\begin{array}{c}\mathbf{O}-\mathbf{H} \cdots \mathbf{O} / \mathbf{N}- \\
\mathbf{H} \cdots \mathbf{O}(\hat{\AA})\end{array}$}} & \multirow{3}{*}{$\begin{array}{c}\mathbf{C u} \cdots \mathbf{C u} \\
(\mathbf{A})\end{array}$} & \multicolumn{2}{|c|}{ Magnetic } \\
\hline & & & & & & $J_{\mathbf{~ c m}^{-1}}$ & $\boldsymbol{\Theta} \mathbf{K}$ \\
\hline \multirow[t]{2}{*}{1.} & EJEMEN $^{14}$ & $\left\{\cdots \mathrm{O}-\mathrm{H}{ }^{\cdots} \mathrm{O}-\mathrm{Cu}-\mathrm{N}-\mathrm{N}-\mathrm{H}\right\}_{2}$ & 2.735 & 2.716 & & -3.0 & \\
\hline & & \multicolumn{6}{|c|}{$\mathbf{O}-\mathbf{H} \cdots \mathbf{O}(\AA)$} \\
\hline 2. & KUBVAF01 $^{15}$ & $\{\cdots \mathrm{O}-\mathrm{Cu}-\mathrm{O}-\mathrm{H}\}_{2}$ & & & 5.750 & -0.55 & -1.64 \\
\hline 3. & PEPJOK $^{1}$ & $\{\cdots \mathrm{O}-\mathrm{C}-\mathrm{O}-\mathrm{Cu}-\mathrm{O}-\mathrm{H}\}_{2}$ & & & 4.901 & -6.83 & \\
\hline 4. & BUQLIJ $^{2}$ & $\{\cdots \mathrm{O}-\mathrm{C}-\mathrm{O}-\mathrm{Cu}-\mathrm{O}-\mathrm{H}\}_{2}$ & & & 4.889 & -6.25 & \\
\hline 5. & FUTCON $^{3}$ & $\{\cdots \mathrm{O}-\mathrm{Cu}-\mathrm{O}-\mathrm{H}\}_{2}$ & & & 4.889 & -19.8 & \\
\hline 6. & $\mathrm{KEDNIR}^{4}$ & $\{\cdots \mathrm{O}-\mathrm{Cu}-\mathrm{O}-\mathrm{H}\}_{2}$ & & & 4.079 & -13.2 & \\
\hline 7. & FAXGOA $^{5}$ & $\{\cdots \mathrm{O}-\mathrm{Cu}-\mathrm{O}-\mathrm{H}\}_{2}$ & & & 3.893 & -49 & \\
\hline 8. & PUQSUQ $^{6}$ & $\{\cdots \mathrm{O}-\mathrm{Cu}-\mathrm{O}-\mathrm{H}\}_{2}$ & & & 4.085 & -12.5 & \\
\hline 9. & KAYJAW $^{16}$ & $\{\cdots \mathrm{O}-\mathrm{C}-\mathrm{C}-\mathrm{C}-\mathrm{C}-\mathrm{N}-\mathrm{Cu}-\mathrm{O}-\mathrm{H}\}_{2}$ & & & 7.960 & 17.2 & -0.21 \\
\hline 10. & KAYJEA $^{16}$ & $\{\cdots \mathrm{O}-\mathrm{C}-\mathrm{O}-\mathrm{Cu}-\mathrm{O}-\mathrm{H}\}$ & & & 7.234 & -4.24 & \\
\hline \multirow[t]{2}{*}{11.} & IBAJIG $^{7}$ & $\left\{\cdots \mathrm{O}-\mathrm{N}-(\mathrm{O})_{2}-\mathrm{Cu}-\mathrm{O}-\mathrm{H}\right\}_{2}$ & & & 6.255 & -11.4 & \\
\hline & & \multicolumn{6}{|c|}{$\mathbf{N}-\mathbf{H} \cdots \mathbf{O}(\AA)$} \\
\hline 12. & UWDOG01 17 & $\left\{\cdots \mathrm{O}-\mathrm{Cl}-(\mathrm{O})_{2} \cdots \mathrm{H}-\mathrm{N}-\mathrm{Cu}-\mathrm{N}-\mathrm{H}\right\}_{2}$ & & & 8.271 & -0.38 & -0.47 \\
\hline 13. & FIJTUP $^{18}$ & $\{\cdots \mathrm{O}-\mathrm{C}-\mathrm{O}-\mathrm{Cu}-\mathrm{N}-\mathrm{N}-\mathrm{H}\}_{2}$ & & & 4.430 & -3.25 & \\
\hline 14. & AMORCU $^{19}$ & $\{\cdots \mathrm{O}-\mathrm{Cu}-\mathrm{N}-\mathrm{H}\}_{2}$ & & & 4.244 & -4.93 & -6.45 \\
\hline
\end{tabular}

\subsection{Dimer with $\mathrm{O}-\mathrm{H} \cdots \mathrm{O}$ and $\mathrm{N}-\mathrm{H} \cdots \mathrm{O}$ Hydrogen Bond}

In $\mathrm{H}$-bonded EJEMEN ${ }^{14}$, oxygen atom of coordinated nitrate and lattice methanol forms $\mathrm{O}-\mathrm{H}^{\cdots} \mathrm{O}$ hydrogen bonds, and the nitrogen atom of ligand and oxygen atom of lattice methanol forms $\mathrm{N}-\mathrm{H} \cdots \mathrm{O}$ hydrogen bond (Fig. 1). The exchange pathways are

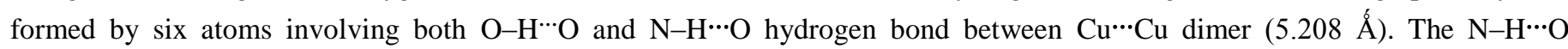
hydrogen bond between dimer shows weak antiferromagnetic interaction having $\mathrm{J}=-3.0 \mathrm{~cm}^{-1}$.

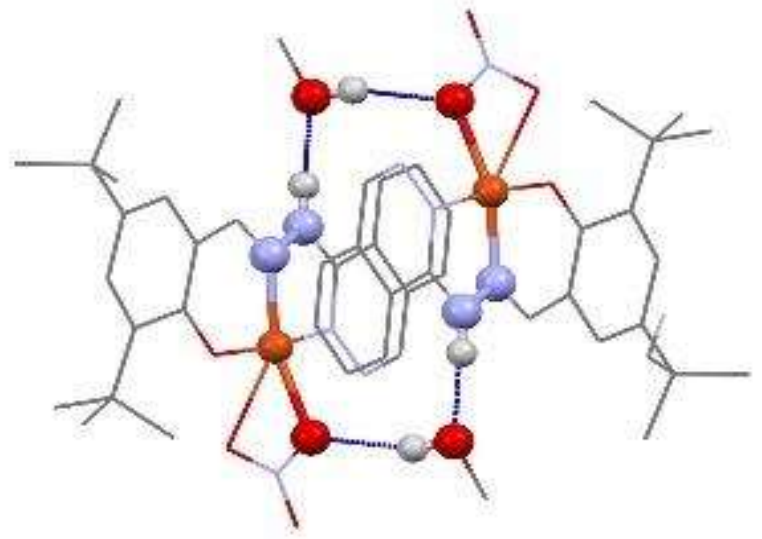

Fig. 1 Copper dimer of EJEMEN: $\{\cdots \mathrm{O}-\mathrm{H} \cdots \mathrm{O}-\mathrm{Cu}-\mathrm{N}-\mathrm{N}-\mathrm{H}\}_{2}$ with antiferromagnetic property

\subsection{Dimers with O-H*O Hydrogen Bond}

The KUBVAF0 $1{ }^{15}$ forms a 1D structure by the arrangement of coordinated carboxylate oxygen and water hydrogen bond with alternate $\{\cdots \mathrm{H}-\mathrm{N}-\mathrm{C}=\mathrm{O}\}$ and $\{\cdots \mathrm{O}-\mathrm{Cu}-\mathrm{O}-\mathrm{H}\}$ metal-organic supramolecular synthon (Fig. 2a), the structure of the crystal contains

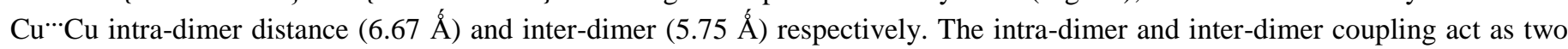
antiferromagnetic exchange pathways, $\mathrm{J}=-0.53 \mathrm{~cm}^{-1}$ indicates antiferromagnetic inter-dimer interaction is stronger than intradimer.

In the crystal structure of PEPJOK ${ }^{1}$ carboxyl oxygen of methoxy salicylate anion forms $\{\cdots \mathrm{O}-\mathrm{C}-\mathrm{O}-\mathrm{Cu}-\mathrm{O}-\mathrm{H}\}$ stronger interdimer interaction $(\mathrm{Cu} \cdots \mathrm{Cu}, 4.901 \AA$ Á) with a water molecule (Fig. 2b).

The BUQLIJ ${ }^{2}$ complex forms a strong hydrogen bond between an axial water molecule and the carboxylate oxygen atom forms $\mathrm{O}-\mathrm{C}-\mathrm{O}-\mathrm{Cu}-\mathrm{O}-\mathrm{H}\}$ metal-organic supra-molecular synthon giving antiferromagnetic interactions; copper ions connect to the equatorial ligand through hydrogen bond which shows antiferromagnetic coupling (Fig. 2c). 


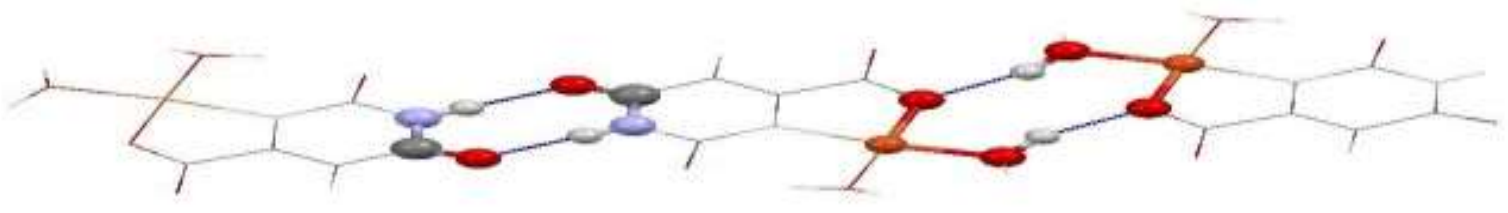

(a)

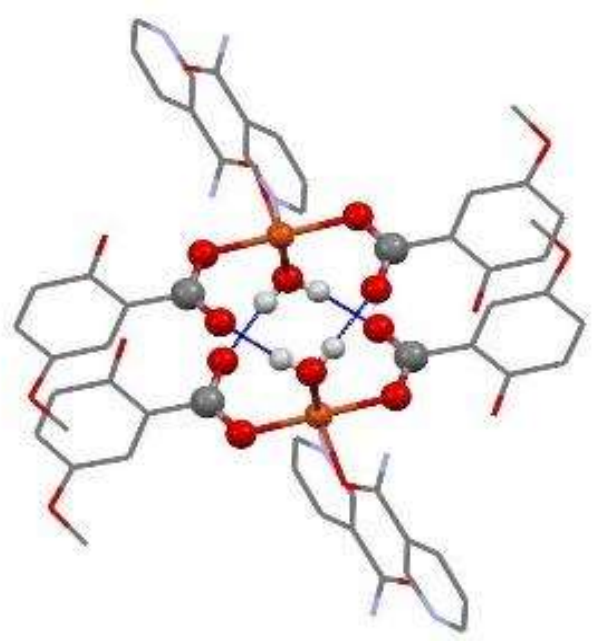

(b)

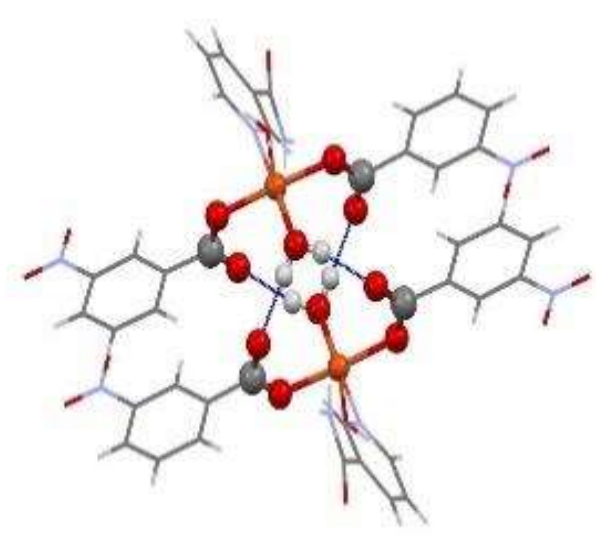

(c)

Fig. 2 Copper dimer of (a) KUBVAF01: $\{\cdots \mathrm{H}-\mathrm{N}-\mathrm{C}-\mathrm{O}\}_{2}$ and $\{\cdots \mathrm{O}-\mathrm{Cu}-\mathrm{O}-\mathrm{H}\}_{2}$; (b) PEPJOK and (c) BUQLIJ with $\{\cdots \mathrm{O}-\mathrm{C}-$ $\mathrm{O}-\mathrm{Cu}-\mathrm{O}-\mathrm{H}\}_{2}$ with antiferromagnetic property

In $\mathrm{FUTCON}^{3}$, coordinated water forms $\mathrm{O}-\mathrm{H}^{\cdots} \mathrm{O}$ hydrogen bond with lattice water molecules and lattice perchlorate anion. $\mathrm{Cu} \cdots \mathrm{Cu}$ $(4.889 \AA)$ is connected by strong $\{\cdots \mathrm{O}-\mathrm{Cu}-\mathrm{O}-\mathrm{H}\}$ hydrogen bond interactions representing antiferromagnetic exchange pathways (Fig. 3a).

The $\{\cdots \mathrm{O}-\mathrm{Cu}-\mathrm{O}-\mathrm{H}\}$ dimer in $\mathrm{KEDNIR}^{4}$ is formed by an intra-dimer bond between a water molecule and the apical oxygen atom of phenolate. This metal-organic supramolecular synthon with $\mathrm{Cu}^{\cdots} \mathrm{Cu}$ dimer $(4.079 \AA$ Á) center provides antiferromagnetic interaction $\left(J=-13.2 \mathrm{~cm}^{-1}\right)$, (Fig. 3b).

Strong $\mathrm{N}-\mathrm{H}^{\cdots} \mathrm{O}$ hydrogen bond is formed between the coordinated nitrogen atom and the oxygen atom of the sulfate molecule in FAXGOA ${ }^{5}$. The mononuclear molecules are joined by $\mathrm{O}-\mathrm{H}^{\cdots} \mathrm{O}$ hydrogen bond with $\mathrm{Cu} \cdots \mathrm{Cu}$ distance $3.893 \AA$ (Fig. $3 \mathrm{c}$ ). The interaction between hydrogen bond shows strong antiferromagnetic having $\mathrm{J}=-49 \mathrm{~cm}^{-1}$.

In PUQSUQ ${ }^{6}$ phenoxo oxygen and coordinated water molecules form a strong intra-dimer $\mathrm{O}-\mathrm{H}^{\cdots}{ }^{\cdots} \mathrm{O}$ hydrogen bond. The magnetic exchange interaction is implemented from this hydrogen bond. (Fig. 3d). This hydrogen bond between $\mathrm{Cu}^{\mathrm{II}}$ atom $(\mathrm{Cu} \cdots \mathrm{Cu}$; 4.085 Á) shows weak antiferromagnetic exchange pathways $\left(\mathrm{J}=-12.5 \mathrm{~cm}^{-1}\right)$. 


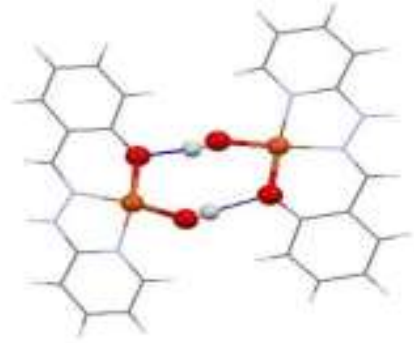

(a)

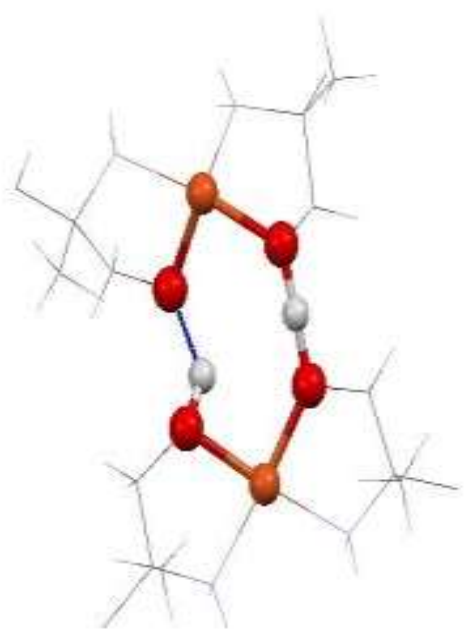

(c)



(b)

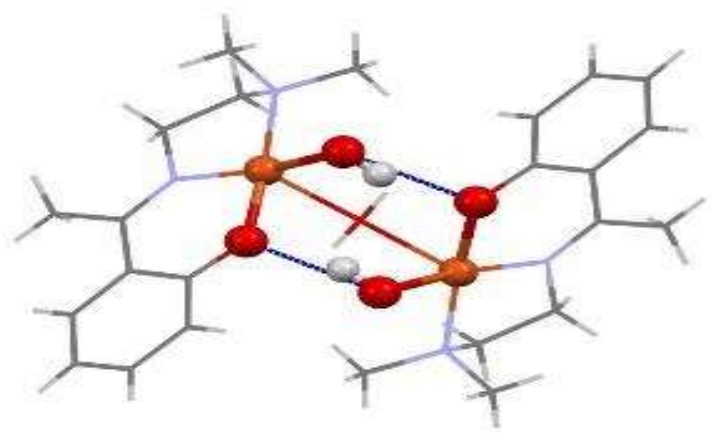

(d)

Fig. 3 Architecture sustained by $\{\cdots \mathrm{O}-\mathrm{Cu}-\mathrm{O}-\mathrm{H}\}_{2}$ synthons: (a) FUTCON and (b) KEDNIR with intermolecular antiferromagnetic interaction; (c) FAXGOA with intramolecular strong antiferromagnetic interaction; and (d) PUQSUQ with intermolecular weak antiferromagnetic interaction

In $\mathrm{KAYJAW}^{16}$, $\mathrm{O}-\mathrm{H}^{\cdots} \mathrm{O}$ hydrogen bond is between the apical water hydrogen atom and a basal anionic ligand oxygen atom. The crystal shows ferromagnetic $\left(\mathrm{J}=17.20 \mathrm{~cm}^{-1}\right)$ exchange coupling through eight-member dimer $\{\mathrm{Cu}-\mathrm{O}-\mathrm{H} \cdots \mathrm{O}-\mathrm{C}-\mathrm{C}-\mathrm{C}-\mathrm{C}-\mathrm{N}-\mathrm{Cu}\}$ (Fig. 4a) having $\mathrm{Cu} \cdots \mathrm{Cu}(7.960 \AA ̊)$.

In KAYJEA ${ }^{16}$, the oxygen atom of oxalate and water hydrogen atoms link to form $\mathrm{O}-\mathrm{H}^{\cdots} \mathrm{O}$ hydrogen bond resulting $1 \mathrm{D}$ chain. KAYJEA have two intermolecular $\mathrm{O}-\mathrm{H}^{\cdots} \mathrm{O}$ hydrogen bond, the shortest $\mathrm{O} \cdots \mathrm{O}$ bond shows weak intermolecular antiferromagnetic interaction $\left(\mathrm{J}=-4.24 \mathrm{~cm}^{-1} ; \mathrm{Cu} \cdots \mathrm{Cu}=7.234 \AA\right.$ ) through $\left\{\mathrm{Cu}-\mathrm{O}-\mathrm{H}^{\cdots}{ }^{\cdots} \mathrm{O}-\mathrm{C}-\mathrm{O}-\mathrm{Cu}\right\}$ metal-organic supramolecular synthon $($ Fig. $4 b)$.

$\mathrm{IBAJIG}^{7}$ crystal is formed by basal ligand and an apical water molecule. The oxygen atom of non-coordinated nitrate ion forms a strong $\mathrm{O}-\mathrm{H}^{\cdots} \mathrm{O}$ hydrogen bond with the hydrogen of coordinated water molecule resulting in the 1D chain. IBAJIG have two types of intra and inter $\mathrm{Cu} \cdots \mathrm{Cu}$ dimer interaction, the shortest intermolecular dimer $6.255 \AA$ involves six atoms $\left\{\cdots \mathrm{O}-\mathrm{N}-(\mathrm{O})_{2}-\mathrm{Cu}-\right.$ $\mathrm{O}-\mathrm{H}$ \} metal-organic synthon giving $\mathrm{J}=-11.40 \mathrm{~cm}^{-1}$ reveals antiferromagnetic exchange pathways (Fig. 4c); it is more efficient interaction. 


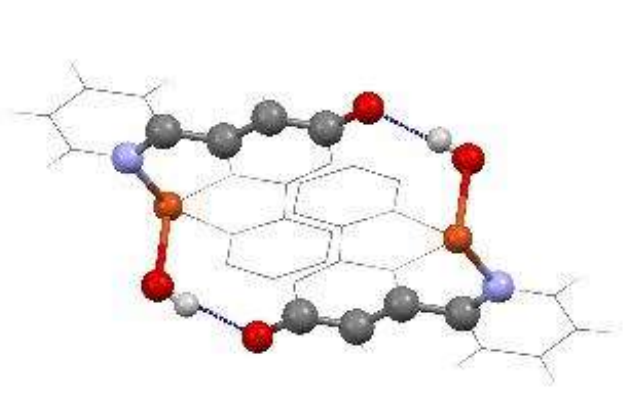

(a)

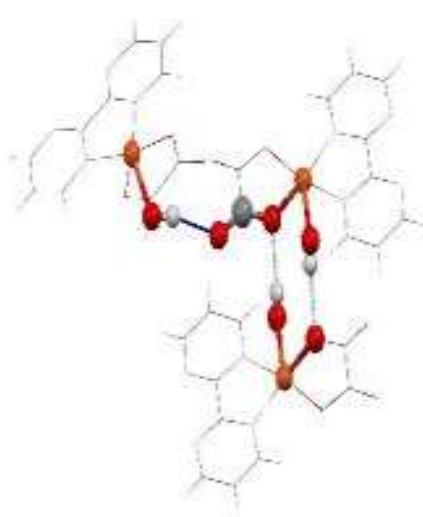

(b)

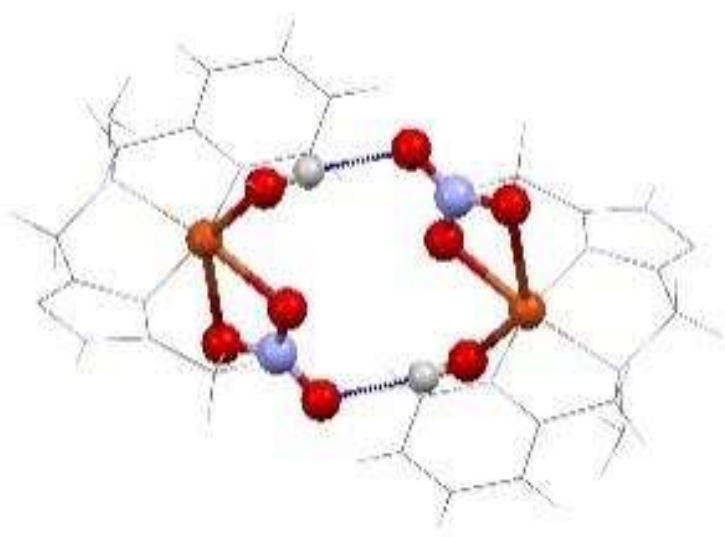

(c)

Fig. 4 Copper dimer of (a) KAYJAW- $\{\cdots \mathbf{O}-\mathrm{C}-\mathrm{C}-\mathrm{C}-\mathrm{C}-\mathrm{N}-\mathrm{Cu}-\mathrm{O}-\mathrm{H}\}_{2}$ with ferromagnetic; (b) KAYJEA- $\{\cdots \mathrm{O}-\mathrm{C}-\mathrm{O}-\mathrm{Cu}-$ O-H $\}$; (c) IBAJIG- $\left\{\cdots \mathrm{O}-\mathrm{N}-(\mathrm{O})_{2}-\mathrm{Cu}-\mathrm{O}-\mathrm{H}\right\}_{2}$ with weak antiferromagnetic property

\subsection{Dimers with $\mathbf{N}-\mathrm{H}^{\cdots} \mathrm{O}$ Hydrogen Bond}

In the structure of UWVDOG $01{ }^{17}$ hydrogen bond links anion and cation through $\mathrm{N}-\mathrm{H}^{\cdots} \mathrm{O}$ synthon (Fig. 5a) which forms an antiferromagnetic exchange pathway. The distance between $\mathrm{Cu}{ }^{\cdots} \mathrm{Cu}$ is $8.2714 \AA$ which causes weak antiferromagnetic coupling due to poor magnetic orbital overlapping. This interaction is through the perchlorate anion and hydrogen bond in the crystal lattice.

In FIJTUP ${ }^{18}$ the NH group of hydrazone and the oxygen atom of coordinated acetate ion forms $\mathrm{N}-\mathrm{H}^{\cdots \cdots} \mathrm{O}$ hydrogen bond (Fig. $5 \mathrm{~b}$ ). The dimer $\left(\mathrm{Cu}{ }^{\cdots} \mathrm{Cu} ; 4.430 \AA \hat{)}\right)$ forms by six atom long interaction pathways $\{\cdots \mathrm{O}-\mathrm{C}-\mathrm{O}-\mathrm{Cu}-\mathrm{N}-\mathrm{N}-\mathrm{H}-\}$ giving intermolecular antiferromagnetic exchange coupling $\left(J=-3.25 \mathrm{~cm}^{-1}\right)$. 


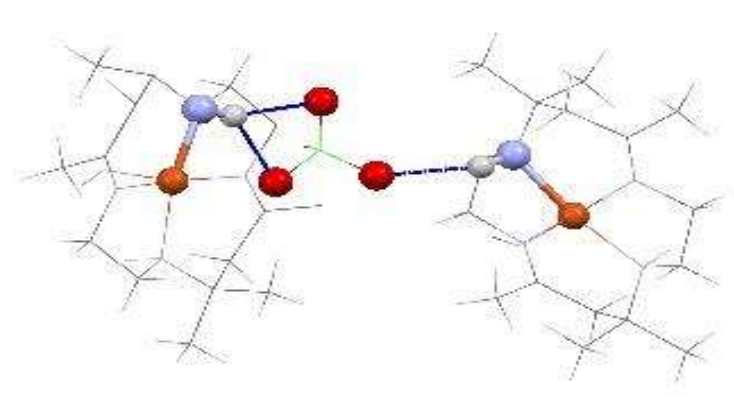

(a)



(b)

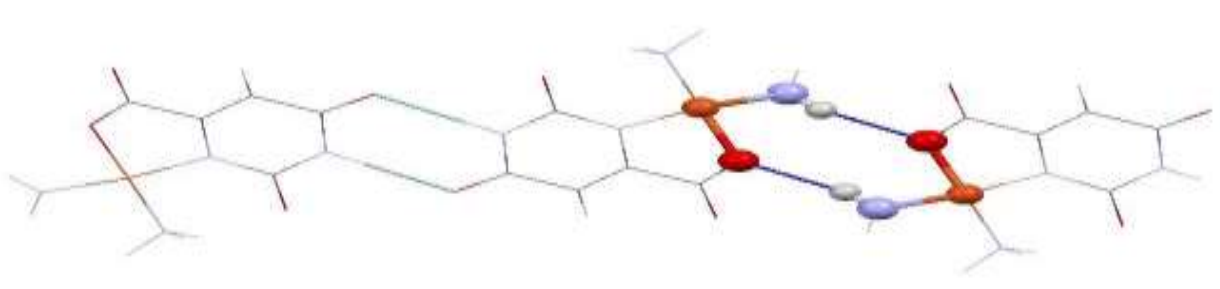

(c)

Figure 5 Copper dimer involving $\mathrm{N}-\mathrm{H}^{\cdots} \mathrm{O}$ of (a) UWDOG01: $\left\{\cdots \mathrm{O}-\mathrm{Cl}-(\mathrm{O})_{2} \cdots \mathrm{H}-\mathrm{N}-\mathrm{Cu}-\mathrm{N}-\mathrm{H}\right\}_{2}$ with weak antiferromagnetic interaction; (b) FIJTUP: $\{\cdots \mathrm{O}-\mathrm{C}-\mathrm{O}-\mathrm{Cu}-\mathrm{N}-\mathrm{N}-\mathrm{H}\}_{2}$ with the antiferromagnetic property; (c) $\mathrm{AMORCU}:\{\cdots \mathrm{O}-\mathrm{Cu}-\mathrm{N}-\mathrm{H}\}_{2}$ with the strong antiferromagnetic property.

The crystal structure of AMORCU ${ }^{19}$ involves $\mathrm{O}-\mathrm{H}^{\cdots} \mathrm{N}$ hydrogen bond between coordinated ammonium ligand and uncoordinated carboxylate oxygen resulting in the 3D network. The $1 \mathrm{D}$ network involves alternate hydrogen bond $\left\{{ }^{\cdots} \mathrm{H}-\mathrm{N}-\mathrm{C}=\mathrm{O}\right\}$ and $(\cdots \mathrm{O}-\mathrm{Cu}-$ $\mathrm{N}-\mathrm{H}\}$ as shown in Fig. 5c. The strong interaction $\mathrm{Cu} \cdots \mathrm{Cu}(4.2442 \AA)$, resulting in strong intermolecular antiferromagnetic interaction having $\mathrm{J}=-4.93 \mathrm{~cm}^{-1}$.

\section{CONCLUSION}

All of these structural topographies could be recognized by the hydrogen-bond bridges connecting metal centers which permit magnetic exchange pathways and deliberate materials design. Fig. 6, clearly indicates the relationship between magnetic properties and hydrogen bond parameter ' $\mathrm{d}$ ' in metal-organic synthons of discussed coordination complexes. Most of the complexes show that ' $\mathrm{J}$ ' value will be more towards positive numbers if ' $\mathrm{d}$ ' and $\mathrm{Cu}{ }^{\cdots} \mathrm{Cu}$ distances are in the range of 2.5 to $2.9 \AA$ and 6.5 to $7.9 \AA$ Á respectively. 


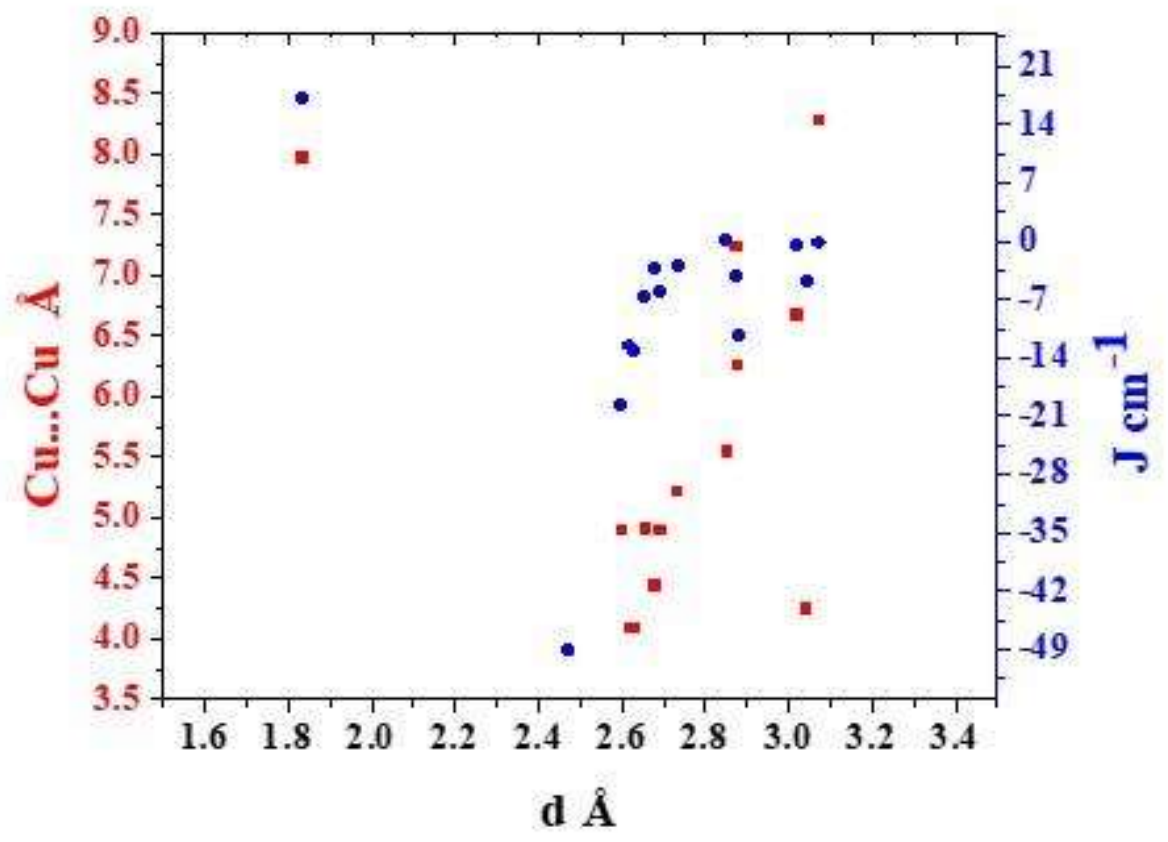

Figure 6 Scatter plot between $\mathrm{J} \mathrm{cm}^{-1}, \mathrm{~d}$ Á, and $\mathrm{Cu} \cdots \mathrm{Cu}$ Á

The present study reveals that metal-organic supramolecular synthons play a significant role in the context of crystal packing, structural diversity, and magnetic exchange pathways. The $\mathrm{H}$-bonded metal-organic supramolecular synthons, for example $\{\cdots \mathrm{O}-$

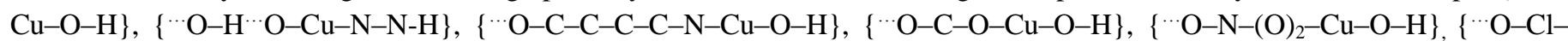
$\left.(\mathrm{O})_{2} \cdots \mathrm{H}-\mathrm{N}-\mathrm{Cu}-\mathrm{N}-\mathrm{H}\right\}$, and $\{\cdots \mathrm{O}-\mathrm{C}-\mathrm{O}-\mathrm{Cu}-\mathrm{N}-\mathrm{N}-\mathrm{H}\}$ are the only artifact in discussed copper complexes for structural diversity, and magnetic properties as well through magnetic-exchange/superexchange phenomenon.

\section{ACKNOWLEDGEMENTS}

Dr. Kafeel Ahmad Siddiqui is thankful to the Council of Scientific and Industrial Research, Department of Science and Technology, New Delhi, India, through the sponsored project with order no. 01(2962)/18/EMR-II dated 01/05/2018 and to Director and Dean (R\&C), National Institute of Technology Raipur, India, for the award of a "Research Seed Grant Project" (Sanction Order No. NITRR/Dean(R\&C)/2017/8300 dated 23/05/2017) to support "Crystal Engineering Research"

\section{REFERENCES}

1. Valigura D, Monco J, Korabik M, Púceková Z, Lis T, Mrozinski J, Melnik M (2006) Eur. J. Inorg. Chem., 2, 3813-3817.

2. Vasková Z, Moncol J, Korabik M, Valigura D, Svorec J, Lis T, Valko M, and Melnik M (2010) Polyhedron, 29, 154163.

3. Tang J, Costa J. S, Golobi A, Kozlevcar B, Robertazzi A, Vargiu A. V, Gamez P, Reedijk J. (2009) J. Inorg. Chem. 48, $5473-547$.

4. $\quad$ Talukder P, Sen S, Mitra S, Dahlenberg L, Desplanches C, and Sutter J. P (2006) Eur. J. Inorg. Chem. 2, 329-333.

5. Muhonen H (1986) Inorg. Chem. 25, 4692-4698.

6. Biswas C, Drew M. G. B, Asthana S, Desplanches C, and Ghosh A (2010) J. Mol. Struct. 965, 39-44.

7. Costa J. S, Bandeira N. A. G, Guennic B. Le, Robert V, Gamez P, Chastanet G, Ortiz-Frade L, Gasque L. Inorg. Chem. 2011, 50, 5696.

8. Desplanches C, Ruiz E, Rodriguez-Fortea A, and Alvarez S (2002) J. Am. Chem. Soc. 124, 5197.

9. Allen F. H (2002) Acta Crystallogr. Sect. B B58, 380-388.

10. Bruno I. J, Cole J. C, Edgington P. R, Kessler M, Macrae C. F, McCabe P, Pearson J, and Taylor R (2002) Acta Crystallogr. Sect. B Struct. Sci. 58, 389-397. 
International Journal of Advances in Scientific Research and Engineering (ijasre), Vol 7 (3), March -2021

11. Macrae C. F, Edgington P. R. McCabe P, Pidcock E, Shields G. P, Taylor R, Towler M, Streek J. van de (2006) J. Appl. Crystallogr. 39, 453-457.

12. Spek A. L (2009) Acta Crystallogr. Sect. D: Biol. Crystallogr. 65, 148-155.

13. Brandenburg K, DIAMOND. Visual Crystal Structure Information System, Version 3.1, Crystal Impact, Bonn, Germany, 1251, 2006.

14. Levchenkov S. I, Popov L. D, Efimov N. N, Minin V. V, Ugolkova E. A. Aleksandrov G. G, Starikova Z. A, Shcherbakov I. N, Ionov A. M, and Kogan V. A (2015) Russ. J. Inorg. Chem 60, 1129-1136.

15. Siddiqui K. A, Lama P, Bieńko A, and Bieńko D (2016) Polyhedron 111, 53-63.

16. Liao C (2005) Chin J. Chem. Soc. 52, 707-716.

17. Suracka K, Bieńko A, Mroziński J, Kruszyński R, Bieńko D, Wojciechowska A (2011) Polyhedron 30, 2550-2557.

18. Levchenkov S. I, Shcherbakov I. N, Popov L. D, Lukov V. V, Minin V. V, Starikova Z. A, Ivannikova E. V, Tsaturyan A. A, Kogan V. A (2013) Inorg. Chim. Acta. 405, 169-175.

19. Yadav A, Lama P, Bieńko A, Bieńko D, and Siddiqui K. A (2018) Polyhedron 141, 247-261. 